\title{
Preoperative White Matter Lesions Are Independent Predictors of Long-Term Survival after Internal Carotid Endarterectomy
}

\author{
Niku Oksala ${ }^{a}$ Marianne Jaroma ${ }^{c}$ Juha-Pekka Pienimäki ${ }^{b}$ \\ Tommi Kuorilehto $^{a}$ Teemu Vänttinen ${ }^{a}$ Antti Lehtomäki ${ }^{a}$ \\ Veli-Pekka Suominen $^{a}$ Prasun Dastidar $^{b}$ Kimmo Mäkinen ${ }^{c}$ \\ Timo Erkinjunttid, e Juha-Pekka Salenius ${ }^{a}$ \\ a Department of Vascular Surgery, Tampere University Hospital and Medical School, Surgery, \\ University of Tampere, and begional Imaging Unit, Tampere University Hospital, Tampere, \\ cHeart Center, Department of Vascular Surgery, Kuopio University Hospital, Kuopio, and \\ ${ }^{\mathrm{d}}$ Department of Neurology, Helsinki University Central Hospital, and e Department of \\ Neurological Sciences, University of Helsinki, Helsinki, Finland
}

\section{Key Words}

Carotid artery stenosis - White matter lesions · Carotid endarterectomy

\begin{abstract}
Background: Cerebral white matter lesions (WMLs) predict long-term survival of conservatively treated acute stroke patients with etiology other than carotid stenosis. In carotid endarterectomy patients, WMLs are associated with severe carotid stenosis and unstable plaques, with the risk of perioperative complications and with increased 30-day perioperative risk of death. However, no data exist on their effect on postoperative long-term survival, a factor important when considering the net benefit from carotid endarterectomy. Whether this effect is independent of classical risk factors and indications for surgery is not known either. We hypothesized that WMLs could be evaluated from preoperative routine computed tomography (CT) scans and are predictors of postoperative survival, independent of classical cardiovascular risk factors, indication category and degree of carotid stenosis. Methods: A total of 353 of 481 (73.4\%) consecutive patients subjected to carotid endarterectomy due to different indications, i.e. asymptomatic stenosis $(n=28,7.9 \%)$, amaurosis fugax $(n=52,14.7 \%)$, transient
\end{abstract} Juha-Pekka Salenius share senior authorship. 
Oksala et al.: Preoperative White Matter Lesions Are Independent Predictors of Long-Term Survival after Internal Carotid Endarterectomy

ischemic attack ( $n=135,38.2 \%)$ or ischemic stroke $(n=138,39.1 \%)$, from prospective vascular registries during the years 2001-2010 with digital preoperative CT scans, were included in the study. WMLs were rated by a radiologist (Wahlund criteria) in a blinded fashion. Internal carotid artery (ICA) stenoses were angiographically graded (<50, 50-69, 70-99 and 100\%). Odds ratios (ORs) and hazard ratios (HRs) are reported (ORs and HRs $\leq 1$ indicate a beneficial effect). The median follow-up time was 67 months (interquartile range 45.5, range 0-129 months). Spearman's rho was used to estimate intraobserver agreement. Binary logistic regression was performed to analyze the association of risk factors with WMLs. Cox regression proportional hazards analysis was used to study the effect of different factors on survival. Results: WML severity could be assessed with a substantial intraobserver agreement (Spearman's rho $0.843, p<0.0001)$. Only age (OR 1.10, 95\% CI 1.06-1.15; $p<0.0001$ per year), degree of ipsilateral ICA stenosis (OR 2.22, 95\% CI 1.08-4.55; $p<0.05$ per stenosis grade) and indication category (OR 1.63, 95\% CI 1.19-2.24; $\mathrm{p}<0.01$ per category) remained independently associated with WMLs. Age (HR 1.04, 95\% CI 1.01-1.08; $\mathrm{p}<0.05$ per year), diabetes (HR 1.59, 95\% CI 1.01-2.49; $p<0.05$ ), peripheral arterial disease (HR 2.47, 95\% CI 1.46-4.15; $p<0.01$ ), degree of ipsilateral ICA stenosis (HR 2.56, 95\% CI 1.12-5.87; $\mathrm{p}<0.05$ per stenosis grade) and WMLs (HR 3.83, 95\% CI 1.17-12.5; $p<0.05$ ) remained independently associated with increased long-term mortality. Conclusions: WMLs in a preoperative CT scan provide a substantially reliable estimate of postoperative long-term survival of carotid endarterectomy patients independent of currently used criteria, i.e. cardiovascular risk factors, indication category and degree of ipsilateral ICA stenosis.

(C) 2014 S. Karger AG, Basel

\section{Introduction}

White matter lesions (WMLs) are a more common finding in ischemic stroke patients than in other populations [1]. WMLs are closely associated with aging, are a surrogate of small-vessel disease and occur in patients with multiple risk factors for atherosclerosis [2].

In the general population, in subjects 65-84 years of age, mild or moderate WMLs are found in up to every third subject [3]. WMLs predict impairment of functional status and hospitalization [4], as well as mortality of elderly people without a history of stroke [5-8] and both mortality [9-11] and recurrent strokes $[12,13]$ in patients with acute stroke. The association of WMLs with poor long-term survival was independent of classical cardiovascular risk factors [9].

Previous data on the effect of WMLs in carotid surgery patients are limited. In ischemic stroke patients, stroke subtype is a strong determinant of new vascular events and survival [14]. Therefore, existing knowledge on stroke patients of other etiologies cannot be directly extrapolated to those with large artery atherosclerosis of the carotid region fulfilling indications for carotid surgery. Previously, WMLs were associated with severe carotid stenosis [15] and unstable plaques [16], with the risk of perioperative complications and increased bloodbrain permeability [17], with the need for perioperative shunting [18] and with increased risk of periprocedural stroke in the International Carotid Stenting Study [19]. Therefore, it was concluded that the presence of WMLs should be considered when selecting patients for carotid revascularization [19]. In the North American Symptomatic Carotid Endarterectomy Trial (NASCET), severe WMLs were associated with increased 30-day perioperative risk of any stroke or death and increased risk of recurrent stroke within 3 years from operation [20]. In patients with asymptomatic or symptomatic carotid stenosis, those with multiple cardiovascular risk factors had impaired survival in a 5-year follow-up [21, 22]. 
At present, WMLs are not evaluated before carotid surgery and no data exist on their effect on postoperative long-term survival, a factor important when considering the net benefit from carotid endarterectomy. Whether this effect is independent of classical risk factors and indications for surgery is not known either. We hypothesized that WMLs could be evaluated from digital preoperative routine computed tomography (CT) scans and are predictors of postoperative survival, independent of classical cardiovascular risk factors, indication category and degree of carotid stenosis.

\section{Materials and Methods}

Consecutive patients $(\mathrm{n}=481)$ from the prospective vascular registries of Tampere University Hospital (TUH) $(n=313)$ and Kuopio University Hospital $(\mathrm{KUH})(\mathrm{n}=168)$ subjected to carotid endarterectomy during the years 2001-2010 were selected for the study. During that period, our indications were based on published guidelines [23]. Of these 481 patients, those with a digital preoperative CT scan available $(n=353,73.4 \%)$ comprised the final study population. Cardiovascular risk factors obtained from the vascular registries were defined based on previous diagnosis and current medication as follows: diabetes mellitus (DM; diagnosis/insulin or oral hypoglycemic medication), arterial hypertension (AHT; diagnosis/antihypertensive medication), cardiac risk factor (diagnosis of myocardial infarction, coronary intervention, angina pectoris, ischemia on electrocardiography, or congestive heart failure), pulmonary risk factor (diagnosis of chronic obstructive pulmonary disease), renal risk factor (diagnosis of renal insufficiency), peripheral arterial disease (PAD; diagnosis/peripheral vascular intervention or amputation) and dyslipidemia (diagnosis/antihyperlipidemic medication). Smoking was defined as smoking within the last 5 years or current smoking. The study was approved by the ethics committee of TUH and KUH.

\section{Radiological Assessment}

All patients were routinely subjected to brain CT and CT angiography using 256 slices of $1 \mathrm{~mm}$ thickness. Internal carotid artery (ICA) stenoses were determined (NASCET criteria) and categorized $(<50,50-69,70-99$ and $100 \%)$ [24] by a neurointerventional radiologist (J.P.P.). The brain CTs were rated in a blinded fashion by an interventional radiologist (J.P.P.) according to the Wahlund criteria (no lesions, focal lesions, beginning confluence, and diffuse confluence) [25]. Seventy CT scans were first randomly selected and the analysis performed in a random and blinded fashion for a total of three times for each scan. A substantial intraobserver agreement was achieved for the Wahlund criteria (Spearman's rho 0.843, $\mathrm{p}<0.0001$ ). After the intraobserver agreement analysis, the rater proceeded with the rest of the scans.

\section{Survival and Causes of Death}

Comprehensive long-term survival data on the status of the patients (alive/dead) and date of death were obtained from the databases of the TUH and KUH on December 31, 2012. These databases provided full coverage of all the patients included in the study. The median follow-up time was 67 months (interquartile range 45.5, range 0-129 months). At the end of the follow-up, 89 patients were dead (25.2\%). No patients were lost to follow-up. The outcome event was all-cause death. The causes of death based on the International Statistical Classification of Diseases and Related Health Problems (on ICD-9 and ICD-10) were obtained and divided further into cardiac (coronary artery disease, valvular heart disease, arrhythmia and congestive heart disease), cerebral (ischemic or hemorrhagic stroke, cerebral bleeding, vascular dementia), peripheral vascular (PAD, aneurysms), cancer, infection, trauma and other categories (Statistics Finland). 
Oksala et al.: Preoperative White Matter Lesions Are Independent Predictors of Long-Term Survival after Internal Carotid Endarterectomy

\section{Statistical Analysis}

According to power analysis, 300 patients were needed to achieve a power of 0.9 to detect a significant difference in postoperative survival between different original Wahlund WML categories. Spearman's rho was used to estimate intraobserver agreement. The $\chi^{2}$ test was performed to compare categorical variables. Continuous variables were analyzed with the Kruskall-Wallis test. Binary logistic regression was used to analyze the association of risk factors with WMLs and the Kaplan-Meier log rank survival analysis to estimate mean survival time. The Cox regression proportional hazards analysis was carried out to study the effect of different factors on survival. The factors were tested for the proportional hazards assumption and this was met for all the factors included in multivariate models. WML severity was further categorized as no lesions versus any lesion (focal lesions and beginning and diffuse confluence) since according to the Cox regression proportional hazards analysis, evidence of any WML was associated with impaired survival. Since data from two separate sites were used (TUH and $\mathrm{KUH}$ ), all analyses were repeated adjusting for study site.

\section{Results}

\section{Patient Characteristics}

There were $56(15.9 \%)$ patients without any WMLs. In univariate analyses, compared with those without lesions, patients with WMLs were older $(p<0.0001)$, had more seldom dyslipidemia $(p<0.05)$ and were more seldom smokers $(p<0.01)$. Ischemic stroke and transient ischemic attack (TIA) were more frequent in patients with WMLs. Amaurosis fugax was less frequent in patients with WMLs $(\mathrm{p}<0.01)$ (table 1$)$.

\section{Association of Patient Demographics, Risk Factors and Indication for Surgery with}

Focal WMLS

In univariate analyses, increasing age (OR 1.11; 95\% CI 1.07-1.15, $\mathrm{p}<0.0001$ per year), dyslipidemia (OR 0.50; 95\% CI 0.26-0.94), smoking (OR 0.38; 95\% CI 0.21-0.68, p < 0.01), degree of ipsilateral ICA stenosis (OR 1.94; 95\% CI 1.01-3.73, p < 0.05) and indication category (OR 1.65; 95\% CI 1.23-2.22, $\mathrm{p}<0.01$ per category) were associated with WMLs (table 2). In multivariate analyses including significant factors from univariate analyses, only age (OR 1.10; 95\% CI 1.06-1.15, p < 0.0001), degree of ipsilateral ICA stenosis (OR 2.22; 95\% CI 1.08$4.55, \mathrm{p}<0.05$ ) and indication category (OR 1.63; 95\% CI 1.19-2.24, $\mathrm{p}<0.05$ per category) remained independently associated with WMLs (table 2). Study site did not affect the results of the multivariate analyses.

\section{Association of Preoperative WMLs with Long-Term Mortality}

According to the Kaplan-Meier log rank analysis, those with any WML had a mean survival of 98.4 months (95\% CI 93.3-103.6) as opposed to 118.5 months (95\% CI 112.4-124.5) in those without any lesions $(\mathrm{p}<0.01)$. In the Cox proportional hazards univariate analyses, age [hazard ratio (HR) 1.05; 95\% CI 1.03-1.07, p < 0.0001 per year], DM (HR 1.62; 95\% CI 1.14$2.31, \mathrm{p}<0.01$ ), cardiac risk factor (HR 1.60; 95\% CI 1.13-2.27), renal risk factor (HR 2.52; 95\% CI 1.11-5.73, p < 0.05), PAD (HR 1.95; 95\% CI 1.29-2.94, p < 0.01), degree of ipsilateral ICA stenosis (HR 2.64; 95\% CI 1.18-5.91, $\mathrm{p}<0.05$ per stenosis grade) and WMLs (HR 5.97; 95\% CI 1.89-18.9, $\mathrm{p}<0.01$ ) were associated with increased mortality (table 3). In contrast, dyslipidemia (HR 0.71; 95\% CI 0.50-1.00, p < 0.05) and smoking (HR 0.65; 95\% CI 0.43-0.98, $\mathrm{p}<0.05$ ) were associated with decreased mortality (table 3 ).

In multivariate analyses including significant factors from univariate analyses, age (HR 1.04; 95\% CI 1.01-1.08, $\mathrm{p}<0.05$ per year), DM (HR 1.59; 95\% CI 1.01-2.49, $\mathrm{p}<0.05$ ), PAD 


\section{Cerebrovascular \\ Diseases}

Table 1. Characteristics of carotid endarterectomy patients

\begin{tabular}{l|l}
\hline \multicolumn{2}{l}{ Cerebrovasc Dis Extra 2014;4:122-131 } \\
\hline DOI: $10.1159 / 000363128$ & $\begin{array}{l}\text { ( ) 2014 S. Karger AG, Basel } \\
\text { www.karger.com/cee }\end{array}$ \\
\hline
\end{tabular}

Oksala et al.: Preoperative White Matter Lesions Are Independent Predictors of Long-Term Survival after Internal Carotid Endarterectomy

\begin{tabular}{|c|c|c|c|c|}
\hline \multirow[t]{2}{*}{ Risk factor } & \multirow{2}{*}{$\begin{array}{l}\text { All } \\
(n=353)\end{array}$} & \multicolumn{2}{|l|}{ WML } & \multirow[t]{2}{*}{$\mathrm{p}$} \\
\hline & & $\begin{array}{l}\text { no } \\
(n=56)\end{array}$ & $\begin{array}{l}\text { any } \\
(n=297)\end{array}$ & \\
\hline \multicolumn{4}{|l|}{ Age } & $<0.0001$ \\
\hline Median & 71.0 & 63.5 & 73.0 & \\
\hline IQR & 13 & 11 & 11 & \\
\hline Female, $\mathrm{n}$ & 95 (26.9) & $16(28.6)$ & $79(26.6)$ & n.s. \\
\hline $\mathrm{DM}, \mathrm{n}$ & $102(28.9)$ & $12(21.4)$ & $90(30.3)$ & n.s. \\
\hline AHT, n & $265(75.1)$ & $45(80.4)$ & $220(74.1)$ & n.s. \\
\hline Cardiac, $\mathrm{n}$ & $189(53.5)$ & $31(55.4)$ & $158(53.2)$ & n.s. \\
\hline Dyslipidemia, $\mathrm{n}$ & $212(60.1)$ & $41(73.2)$ & $171(57.6)$ & $<0.05$ \\
\hline Renal, $\mathrm{n}$ & $9(2.5)$ & $2(3.6)$ & $7(2.4)$ & n.s. \\
\hline PAD, n & $48(13.6)$ & $10(17.9)$ & $38(12.8)$ & n.s. \\
\hline Pulmonary, n & 42 (11.9) & 7 (12.5) & 35 (11.8) & n.s. \\
\hline Smoking, n & $99(28.0)$ & $26(46.4)$ & $73(24.6)$ & $<0.01$ \\
\hline \multicolumn{4}{|l|}{ IL stenosis } & n.s. \\
\hline$<50 \%, \mathrm{n}$ & $3(0.9)$ & $1(1.8)$ & $2(0.7)$ & \\
\hline $50-69 \%, \mathrm{n}$ & $44(12.6)$ & $11(20.0)$ & $33(11.2)$ & \\
\hline $70-99 \%, \mathrm{n}$ & $303(86.6)$ & $43(78.2)$ & $260(88.1)$ & \\
\hline $100 \%, \mathrm{n}$ & $0(0)$ & $0(0)$ & $0(0)$ & \\
\hline \multicolumn{4}{|l|}{ CL stenosis } & n.s. \\
\hline$<50 \%, \mathrm{n}$ & $223(63.4)$ & $34(60.7)$ & $189(63.9)$ & \\
\hline $50-69 \%, \mathrm{n}$ & $60(17.0)$ & $9(16.1)$ & $51(17.2)$ & \\
\hline $70-99 \%, \mathrm{n}$ & $56(15.9)$ & $13(23.2)$ & $43(14.5)$ & \\
\hline $100 \%, \mathrm{n}$ & $13(3.7)$ & $0(0)$ & $13(4.4)$ & \\
\hline \multicolumn{4}{|l|}{ Indication category } & $<0.01$ \\
\hline Asymptomatic, $\mathrm{n}$ & $28(7.9)$ & 7 (12.5) & $21(7.1)$ & \\
\hline Amaurosis, $\mathrm{n}$ & $52(14.7)$ & $16(28.6)$ & $36(12.1)$ & \\
\hline TIA, $\mathrm{n}$ & $135(38.2)$ & $20(35.7)$ & $15(38.7)$ & \\
\hline Ischemic stroke, $\mathrm{n}$ & $138(39.1)$ & $13(23.2)$ & $125(42.1)$ & \\
\hline
\end{tabular}

Figures in parentheses are percentages. The category any WML includes focal lesions, and beginning and diffuse confluence according to the Wahlund criteria. Cardiac risk factor: diagnosis of myocardial infarction, coronary intervention, angina pectoris, ischemia on electrocardiography and congestive heart failure. IL = Ipsilateral; CL = contralateral.

(HR 2.47; 95\% CI 1.46-4.15, p < 0.01), degree of ipsilateral ICA stenosis (HR 2.56; 95\% CI $1.12-5.87, \mathrm{p}<0.05$ per stenosis grade) and WMLs (HR 3.83; 95\% CI 1.17-12.5, p < 0.05) remained independently associated with increased mortality (table 3). Study site did not affect the results of the multivariate analyses.

\section{Causes of Death}

During the follow-up, 89 patients of the whole study population $(n=353)$ died. The causes of death were cardiovascular (59.5\%), i.e. cerebral (15.7\%), cardiac (40.4\%), peripheral vascular $(3.4 \%)$, due to cancer $(18.0 \%)$, infectious $(1.1 \%)$, traumatic $(1.1 \%)$ or classified as other causes of death (7.9\%) (table 4$)$. 
Table 2. Association of risk factors with preoperative CT WMLs

\begin{tabular}{lll}
\hline Risk factor & Univariate & Multivariate \\
\hline Age (per year) & $1.11(1.07-1.15)^{* * *}$ & $1.10(1.06-1.15)^{* * *}$ \\
Female gender & $0.91(0.48-1.71)$ & not included \\
DM & $1.59(0.80-3.16)$ & not included \\
AHT & $0.70(0.34-1.42)$ & not included \\
Cardiac & $0.92(0.52-1.63)$ & not included \\
Dyslipidemia & $0.50(0.26-0.94)^{*}$ & $0.54(0.27-1.09)$ \\
Renal & $0.65(0.13-3.22)$ & not included \\
PAD & $0.68(0.31-1.45)$ & not included \\
Pulmonary & $0.94(0.39-2.23)$ & not included \\
Smoking & $0.38(0.21-0.68)^{* *}$ & $0.91(0.45-1.83)$ \\
IL stenosis & $1.94(1.01-3.73)^{*}$ & $2.22(1.08-4.55)^{*}$ \\
CL stenosis & $0.96(0.70-1.32)$ & not included \\
Indication category & $1.65(1.23-2.22)^{* *}$ & $1.63(1.19-2.24)^{* *}$ \\
\hline
\end{tabular}

Figures are ORs with 95\% CIs in parentheses. Binary logistic regression analysis with a 'no lesions' category as a reference. WMLs include focal lesions, and beginning and diffuse confluence according to the Wahlund criteria. The multivariate model was adjusted to the significant factors from the univariate analysis. Cardiac risk factor: diagnosis of myocardial infarction, coronary intervention, angina pectoris, ischemia on electrocardiography and congestive heart failure. IL = Ipsilateral; $\mathrm{CL}=$ contralateral stenosis $(<50 \%, 50-$ 69\%, $70-99 \%, 100 \%)$. Indication category: (1) asymptomatic, (2) amaurosis fugax, (3) TIA, (4) ischemic stroke. ${ }^{*} \mathrm{p}<0.05{ }^{* *} \mathrm{p}<0.01{ }^{* * *} \mathrm{p}<0.0001$.

Table 3. Effect of preoperative CT WMLs on long-term survival in carotid endarterectomy patients

\begin{tabular}{lll}
\hline Risk factor & Univariate & Multivariate \\
\hline Age (per year) & $1.05(1.03-1.07)^{* * *}$ & $1.04(1.01-1.08)^{*}$ \\
Female gender & $0.97(0.65-1.43)$ & not included \\
DM & $1.62(1.14-2.31)^{* *}$ & $1.59(1.01-2.49)^{*}$ \\
AHT & $0.94(0.65-1.37)$ & not included \\
Cardiac & $1.60(1.13-2.27)^{* *}$ & $1.26(0.80-1.99)$ \\
Dyslipidemia & $0.71(0.50-1.00)^{*}$ & $0.82(0.53-1.27)$ \\
Neurological & $0.93(0.64-1.34)$ & not included \\
Pulmonary & $1.22(0.70-2.12)$ & not included \\
Renal & $2.52(1.11-5.73)^{*}$ & $2.16(0.78-6.02)$ \\
PAD & $1.95(1.29-2.94)^{* *}$ & $2.47(1.46-4.15)^{* *}$ \\
Smoking & $0.65(0.43-0.98)^{*}$ & $0.94(0.51-1.73)$ \\
IL stenosis & $2.64(1.18-5.91)^{*}$ & $2.56(1.12-5.87)^{*}$ \\
CL stenosis & $1.15(0.92-1.43)$ & not included \\
Indication category & $1.06(0.89-1.27)$ & not included \\
Any WML & $5.97(1.89-18.9)^{* *}$ & $3.83(1.17-12.5)^{*}$ \\
\hline
\end{tabular}

Figures are HRs with 95\% CIs in parentheses. Cox regression proportional hazards analysis. The multivariate model was adjusted to the significant factors from the univariate analysis. Cardiac risk factor: diagnosis of myocardial infarction, coronary intervention, angina pectoris or ischemia on electrocardiography and congestive heart failure. IL = Ipsilateral; CL = contralateral. Indication category: (1) asymptomatic, (2) amaurosis fugax, (3) TIA, (4) stroke. Any WML includes focal lesions, and beginning and diffuse confluence according to the Wahlund criteria. ${ }^{*} \mathrm{p}<0.05$; ${ }^{*} \mathrm{p}<0.01$; *** $\mathrm{p}<0.0001$. 


\section{Cerebrovascular \\ Diseases}

Table 4. Causes of death in carotid endarterectomy patients

\begin{tabular}{l|l}
\hline Cerebrovasc Dis Extra 2014;4:122-131 \\
\hline DOI: 10.1159/000363128 & $\begin{array}{l}\text { c 2014 S. Karger AG, Basel } \\
\text { www.karger.com/cee }\end{array}$ \\
\hline
\end{tabular}

Oksala et al.: Preoperative White Matter Lesions Are Independent Predictors of Long-Term Survival after Internal Carotid Endarterectomy

\begin{tabular}{lc}
\hline Cause of death & \\
\hline Cardiovascular & $53(59.5)$ \\
$\quad$ Cerebral & $14(15.7)$ \\
$\quad$ Cardiac & $36(40.4)$ \\
$\quad$ Peripheral vascular & $3(3.4)$ \\
Cancer & $16(18.0)$ \\
Infection & $1(1.1)$ \\
Trauma & $1(1.1)$ \\
Other & $7(7.9)$ \\
\hline
\end{tabular}

Figures are numbers with percentages in parentheses.

\section{Discussion}

WMLs, a surrogate of small-vessel disease, are a common finding in preoperative brain CT. They are associated with age, degree of ipsilateral carotid stenosis and indication category (asymptomatic, amaurosis fugax, TIA, and stroke) for the procedure. WMLs provide a substantially reliable estimate of postoperative long-term survival of carotid endarterectomy patients independent of classical cardiovascular risk factors, indication category and degree of ipsilateral carotid stenosis.

Owing to limited data, direct comparison of patient characteristics can only be made with the work of Streifler et al. [20]. Our cohort based on prospective vascular registry data was characterized by more frequent risk factors, especially dyslipidemia. These studies represent two different eras without uniform definitions and treatment guidelines of the risk factors. In Streifler's work, only one third and in our cohort almost $87 \%$ had a carotid stenosis of $>70 \%$. The changes in risk factor management over time have led to a situation, where carotid plaques become symptomatic only at a more severe stenosis grade. The same trend in the prevalence of comorbid conditions and in the degree of symptomatic carotid stenosis can be detected in more recent studies [26-28]. It is noteworthy, however, that some of these studies comprised mainly asymptomatic patients, which is in contrast to our material [28].

Our finding of an association of age with WML severity is in line with previous findings $[20,29]$. In the present study, the previous association of AHT with WMLs $[20,29,30]$ was not replicated, which may be due to heterogeneity of the definition of hypertension including those with diagnosed hypertension under control and those without response. Both the frequency of dyslipidemia and smoking decreased with increasing WML severity, in line with a previous study [20]. Previously, dyslipidemia showed a similar association with WMLs (OR 0.63 ] [30]. These findings in univariate analyses may be explained in two ways. Firstly, during the study period, almost all cerebrovascular patients with dyslipidemia were on statin therapy, which may confer protection against WMLs. Secondly, there is a possible harvesting bias as described in the NASCET study - elderly patients were more likely to be smokers and had dyslipidemia more frequently than younger patients [24]. Interestingly, WMLs are linked to increased risk of vascular deaths [31] and both smoking [32] and dyslipidemia [33] are associated with the occurrence of WMLs. Therefore, due to a possible synergistic effect of these risk factors, those with widespread WMLs and dyslipidemia or smoking may have already deceased due to other cardiovascular causes before the development of carotid disease. Actually, in the present study, the association of dyslipidemia and smoking disappeared in multivariate regression analyses after adjustment to age, ipsilateral stenosis and indication category. Our finding of increased WMLs in patients whose indication was previous stroke is in line with a previous study [34], which showed that the probability of stroke 
Oksala et al.: Preoperative White Matter Lesions Are Independent Predictors of Long-Term Survival after Internal Carotid Endarterectomy

increases with increasing WML severity. Our result of an association of ipsilateral ICA stenosis with WML severity is in line and supported by previous studies [15, 35] although contradicting evidence also exists from CT [30] and MRI studies [36]. While the pathophysiological mechanism behind this phenomenon is not clear, the degree of ICA stenosis may modulate the carotid plaque composition [37] although contradicting evidence also exists [38]. Furthermore, intraplaque hemorrhage [39], unstable plaques [16] and total plaque volume [40] are associated with WML severity.

Our present results in surgical patients are in line with previous findings that WMLs predict poststroke survival in acute stroke patients independent of classical cardiovascular risk factors and that cardiovascular deaths account for the majority of causes of deaths [9]. Our present results are novel since they not only extend the short-term results of the NASCET study analyzing the 30-day perioperative risk and risk of recurrent stroke within 3 years from operation but also provide data on long-term mortality [20]. Furthermore, the International Carotid Stenting Study analyzed the association of WMLs with periprocedural stroke but provided no data on long-term follow-up [19]. Long-term results are important since the limited net benefit from carotid procedures is dependent on the remaining life span of the patient. Furthermore, previous knowledge on the association of WMLs with survival was obtained on stroke patients of other ischemic subtypes (cardioembolism, small-vessel occlusion, stroke of undetermined etiology). Those findings cannot be directly extrapolated to those of patients with large artery atherosclerosis of the carotid region fulfilling indications for carotid surgery since future vascular events and survival vary significantly across different stroke subtypes [14]. We suppose that these data could be utilized in optimal patient selection for surgery especially in patients with asymptomatic stenosis and questionable net benefit from the procedure. Future studies powered to analyze this subgroup are warranted. The probable mechanism by which WMLs impact on mortality is explained by the concept of systemic small-vessel disease $[10,11]$. This is highlighted by a close association of WMLs with impaired kidney function [11]. Our findings highlight the importance to develop strategies to slow down the advancement of WMLs [41], thus possibly resulting in improved survival. When considering the value of WMLs in patient risk stratification, it must also be considered that the procedure itself could induce regression of WMLs [42].

The main shortcoming of the study is the lack of data on incident cardiovascular events, which makes a direct comparison of our results difficult. Although we did not analyze the degree of gray matter lesions, according to our established and consistent indications, only patients with mild-to-moderate strokes were subjected to the procedure. In addition, postoperative CT was not performed routinely and therefore the effect of the operative procedure on WMLs could not be estimated. It must also be emphasized that MRI is the golden standard and more sensitive than CT in the detection of small WMLs while they have provided almost equal value in the detection of widespread WMLs [25]. However, the high availability and small costs of CT make it clinically applicable. All the study participants were of Caucasian origin and may not therefore be generalized to other populations. The strength of the study is comprehensive data with no missing data from two prospective vascular registries. Since the study population was collected from two separate study sites, all the analyses were repeated using a covariate adjusting for study site. Since this adjustment did not alter the results of the multivariate analyses, we consider that study site was not a significant source of bias.

In conclusion, the degree of WMLs, a surrogate of small-vessel disease, can be substantially reliably rated on preoperative routine CT and provides a long-term predictive value independent of classical cardiovascular risk factors, indication category (asymptomatic, amaurosis, TIA or stroke) and ipsilateral ICA stenosis. Therefore, in addition to a patient's symptoms and degree of carotid stenosis, after validation of the results in independent 
cohorts and studies powered to stratify for different indication categories, we suggest that WMLs can also be an important factor to be utilized for the optimal selection of patients for carotid endarterectomy.

\section{Acknowledgements}

This study was supported by grants from the Maire Taponen Foundation; the Emil Aaltonen Foundation, Tampere, and the Medical Research Fund of Tampere University Hospital.

\section{Disclosure Statement}

The authors declare that there are no conflicts of interest.

\section{References}

1 Wen W, Sachdev PS: Extent and distribution of white matter hyperintensities in stroke patients: the Sydney Stroke Study. Stroke 2004;35:2813-2819.

2 Inzitari D: Leukoaraiosis: an independent risk factor for stroke? Stroke 2003;34:2067-2071.

-3 Breteler MM, Van Swieten JC, Bots ML, Grobbee DE, Claus JJ, Van den Hout JH, et al: Cerebral white matter lesions, vascular risk factors, and cognitive function in a population-based study: the Rotterdam Study. Neurology 1994;44:1246-1252.

4 Inzitari D, Simoni M, Pracucci G, Poggesi A, Basile AM, Chabriat H, et al: Risk of rapid global functional decline in elderly patients with severe cerebral age-related white matter changes: the LADIS study. Arch Intern Med 2007;167:881-888.

-5 Kuller LH, Arnold AM, Longstreth WT Jr, Manolio TA, O'Leary DH, Burke GL, et al: White matter grade and ventricular volume on brain MRI as markers of longevity in the cardiovascular health study. Neurobiol Aging 2007;28:1307-1315.

6 Kerber KA, Whitman GT, Brown DL, Baloh RW: Increased risk of death in community-dwelling older people with white matter hyperintensities on MRI. J Neurol Sci 2006;250:33-38.

7 Briley DP, Haroon S, Sergent SM, Thomas S: Does leukoaraiosis predict morbidity and mortality? Neurology 2000;54:90-94.

8 Inzitari D, Cadelo M, Marranci ML, Pracucci G, Pantoni L: Vascular deaths in elderly neurological patients with leukoaraiosis. J Neurol Neurosurg Psychiatry 1997;62:177-181.

-9 Oksala NK, Oksala A, Pohjasvaara T, Vataja R, Kaste M, Karhunen PJ, et al: Age related white matter changes predict stroke death in long term follow-up. J Neurol Neurosurg Psychiatry 2009;80:762-766.

10 Melkas S, Putaala J, Oksala N, Pohjasvaara T, Oksala A, Kaste M, et al: Small-vessel disease relates to poor poststroke survival in a 12-year follow-up. Neurology 2010;76:734-739.

11 Oksala NK, Salonen T, Strandberg T, Oksala A, Pohjasvaara T, Kaste M, et al: Cerebral small vessel disease and kidney function predict long-term survival in patients with acute stroke. Stroke 2010;41:1914-1920.

12 Fu JH, Lu CZ, Hong Z, Dong Q, Luo Y, Wong KS: Extent of white matter lesions is related to acute subcortical infarcts and predicts further stroke risk in patients with first ever ischaemic stroke. J Neurol Neurosurg Psychiatry 2005;76:793-796.

13 Melkas S, Sibolt G, Oksala NKJ, Putaala J, Pohjasvaara T, Kaste M, et al: Extensive white matter changes predict stroke recurrence up to 5 years after a first-ever ischemic stroke. Cerebrovasc Dis 2012;34:191-198.

-14 Ois A, Cuadrado-Godia E, Rodríguez-Campello A, Giralt-Steinhauer E, Jiménez-Conde J, Lopez-Cuiña M, et al: Relevance of stroke subtype in vascular risk prediction. Neurology 2013;81:575-580.

15 Patankar T, Widjaja E, Chant H, McCollum C, Baldwin R, Jeffries S, et al: Relationship of deep white matter hyperintensities and cerebral blood flow in severe carotid artery stenosis. Eur J Neurol 2006;13:10-16.

16 Altaf N, Daniels L, Morgan PS, Lowe J, Gladman J, MacSweeney ST, et al: Cerebral white matter hyperintense lesions are associated with unstable carotid plaques. Eur J Vasc Endovasc Surg 2006;31:8-13.

17 Topakian R, Barrick TR, Howe FA, Markus HS: Blood-brain barrier permeability is increased in normalappearing white matter in patients with lacunar stroke and leucoaraiosis. J Neurol Neurosurg Psychiatry 2010;81:192-197.

18 Arshad A, Altaf N, Goode S, Auer DP, MacSweeney ST: Leukoaraiosis predicts the need for intraoperative shunt placement during carotid endarterectomy. Perspect Vasc Surg Endovasc Ther 2009;21:173-177. 
Oksala et al.: Preoperative White Matter Lesions Are Independent Predictors of

Long-Term Survival after Internal Carotid Endarterectomy

19 Ederle J, Davagnanam I, Van der Worp HB, Venables GS, Lyrer PA, Featherstone RL, et al: Effect of white-matter lesions on the risk of periprocedural stroke after carotid artery stenting versus endarterectomy in the International Carotid Stenting Study (ICSS): a prespecified analysis of data from a randomised trial. Lancet Neurol 2013;12:866-872.

20 Streifler JY, Eliasziw M, Benavente OR, Alamowitch S, Fox AJ, Hachinski VC, et al: Prognostic importance of leukoaraiosis in patients with symptomatic internal carotid artery stenosis. Stroke 2002;33:1651-1655.

21 Wallaert JB, Cronenwett JL, Bertges DJ, Schanzer A, Nolan BW, De Martino R, et al: Optimal selection of asymptomatic patients for carotid endarterectomy based on predicted 5-year survival. J Vasc Surg 2013;58:112128.

22 Reed AB, Gaccione P, Belkin M, Donaldson MC, Mannick JA, Whittemore AD, et al: Preoperative risk factors for carotid endarterectomy: defining the patient at high risk. J Vasc Surg 2003;37:1191-1199.

-23 Liapis CD, Bell PRF, Mikhailidis D, Sivenius J, Nicolaides A, Fernandes E, Fernandes J, et al: ESVS guidelines. Invasive treatment for carotid stenosis: indications, techniques. Eur J Vasc Endovasc Surg 2009;37(4 Suppl):1-19.

24 Alamowitch S, Eliasziw M, Algra A, Meldrum H, Barnett HJ: Risk, causes, and prevention of ischaemic stroke in elderly patients with symptomatic internal-carotid-artery stenosis. Lancet 2001;357:1154-1160.

25 Wahlund LO, Barkhof F, Fazekas F, Bronge L, Augustin M, Sjögren M, et al: A new rating scale for age-related white matter changes applicable to MRI and CT. Stroke 2001;32:1318-1322.

-26 Van Lammeren GW, Moll FL, Blankestijn PJ, De Kleijn DP, Bots ML, Verhaar MC, et al: Decreased kidney function: an unrecognized and often untreated risk factor for secondary cardiovascular events after carotid surgery. Stroke 2011;42:307-312.

27 Protack CD, Bakken AM, Saad WE, Davies MG: Influence of chronic renal insufficiency on outcomes following carotid revascularization. Arch Surg 2011;146:1135-1141.

28 Greenstein AJ, Chassin MR, Wang J, Rockman CB, Riles TS, Tuhrim S, et al: Association between minor and major surgical complications after carotid endarterectomy: results of the New York Carotid Artery Surgery study. J Vasc Surg 2007;46:1138-1144.

29 Chutinet A, Biffi A, Kanakis A, Fitzpatrick KM, Furie KL, Rost NS: Severity of leukoaraiosis in large vessel atherosclerotic disease. Am J Neuroradiol 2012;33:1591-1595.

-30 Streifler JY, Eliasziw M, Benavente OR, Hachinski VC, Fox AJ, Barnett HJ: Lack of relationship between leukoaraiosis and carotid artery disease. The North American Symptomatic Carotid Endarterectomy Trial. Arch Neurol 1995;52:21-24.

-31 Conijn MMA, Kloppenborg RP, Algra A, Mali WPTM, Kappelle LJ, Vincken KL, et al: Cerebral small vessel disease and risk of death, ischemic stroke, and cardiac complications in patients with atherosclerotic disease: the Second Manifestations of ARTerial disease-Magnetic Resonance (SMART-MR) study. Stroke 2011;42:31053109.

- 32 Van Dijk EJ, Prins ND, Vrooman HA, Hofman A, Koudstaal PJ, Breteler MMB: Progression of cerebral small vessel disease in relation to risk factors and cognitive consequences: Rotterdam Scan study. Stroke 2008;39: 2712-2719.

33 Bokura H, Yamaguchi S, Iijima K, Nagai A, Oguro H: Metabolic syndrome is associated with silent ischemic brain lesions. Stroke 2008;39:1607-1609.

-34 Arsava EM, Bayrlee A, Vangel M, Rost NS, Rosand J, Furie KL, et al: Severity of leukoaraiosis determines clinical phenotype after brain infarction. Neurology 2011;77:55-61.

-35 Saba L, Sanfilippo R, Pascalis L, Montisci R, Mallarini G: Carotid artery abnormalities and leukoaraiosis in elderly patients: evaluation with MDCT. AJR Am J Roentgenol 2009;192:W63-W70.

-36 Potter GM, Doubal FN, Jackson CA, Sudlow CL, Dennis MS, Wardlaw JM: Lack of association of white matter lesions with ipsilateral carotid artery stenosis. Cerebrovasc Dis 2012;33:378-384.

37 Sui B, Gao P, Lin Y, Jing L, Qin H, Wang T, et al: Association of plaque compositions and stenosis patterns in carotid bifurcation using MR imaging. Neurol Res 2012;34:366-372.

-38 Patterson AJ, U-King-Im JM, Tang TY, Scoffings DJ, Howarth SP, Graves MJ, et al: Association between white matter ischaemia and carotid plaque morphology as defined by high-resolution in vivo MRI. Eur J Vasc Endovasc Surg 2009;38:149-154.

39 Altaf N, Morgan PS, Moody A, MacSweeney ST, Gladman JR, Auer DP: Brain white matter hyperintensities are associated with carotid intraplaque hemorrhage. Radiology 2008;248:202-209.

-40 Kwee RM, Hofman PAM, Gronenschild EHBM, Van Oostenbrugge RJ, Mess WH, Ter Berg JWM, et al: Association between carotid plaque characteristics and cerebral white matter lesions: one-year follow-up study by MRI. PLoS One 2011;6:e17070.

41 Dufouil C, Chalmers J, Coskun O, Besançon V, Bousser M-G, Guillon P, et al: Effects of blood pressure lowering on cerebral white matter hyperintensities in patients with stroke: the PROGRESS (Perindopril Protection Against Recurrent Stroke Study) Magnetic Resonance Imaging Substudy. Circulation 2005;112:1644-1650.

42 Chuang Y-M, Huang K-L, Chang Y-J, Chang C-H, Chang T-Y, Wu T-C, et al: Immediate regression of leukoaraiosis after carotid artery revascularization. Cerebrovasc Dis 2011;32:439-446. 